\title{
MATHEMATICAL MODELS AND ALGORITHMS OF OPTIMAL LOAD MANAGEMENT OF ELECTRICAL CONSUMERS
}

\author{
K M Reymov¹, G M Turmanova ${ }^{1}$, S K Makhmuthonov², B A Uzakov ${ }^{1}$ \\ ${ }^{1}$ Karakalpak State University, 230100, Uzbekistan, Nukus, Ch. Abdirov St.1 \\ ${ }^{2}$ Tashkent State Technical University named after Islam Karimov, 100095, Uzbekistan, Tashkent, University St. 2A
}

\begin{abstract}
The article investigated the static, dynamic and metrological characteristics of new magnetoelastic force sensors taking into account the distribution of Load profile smoothing based on optimal power management is considered to be one of the main ways to ensure efficient operation of energy systems in the short-term planning. Smoothing load profile with a view to reducing costs can be implemented on the ways in which consumers could be affected by administrative and economic measures. Administrative measures are associated with the forced restriction of consumer loads in certain intervals of the planning period. On the one hand, these measures provide benefits to the power system by smoothing load profile, and on the other hand, they cause damage to consumers. Ultimately, in some cases, the damage may be greater than the benefits as a whole to the power system. Therefore, it is advisable to use them in conditions of shortage of power and electricity in the power system. Optimal planning of short-term regimes of power systems according to received, after alignment, rigid load profile can be carried out by traditional methods. The solution of such a problem can be initially carried out under conditions of non-rigid load profile resulting from the directive use of administrative and economic measures carried out with the help of specially developed models. In this regard, the paper proposes a mathematical model of the problem of optimizing load profile of regulated electrical consumers with optimal planning of short-term power system modes, an algorithm for optimal planning of a short-term power system mode with optimizing load profile of regulated power consumers. And also, algorithms are proposed for accounting for simple and functional constraints in the form of equalities and inequalities when optimizing load profile. The effectiveness of the described algorithm for optimizing the short-term mode of the power system, taking into account the optimal load control of adjustable electric locomotives, has been studied using the example of optimal coverage of the load profile of power system, which contains two consumers with adjustable load profile, and two TPPs. Based on the calculated experimental studies computational qualities, it was determined that the proposed mathematical model of the problem is adequate, the developed algorithms for optimal planning of shortterm power system modes with optimization of load profile of regulated electric consumers and taking into account various types of limitations have high computational qualities.
\end{abstract}

\section{Introduction}

Currently, deterministic mathematical models are mainly used to analyze and optimize the modes of electric power systems (EPS) and networks. In this case, using various iterative methods and corresponding computer programs, the nature of the ongoing process is determined uniquely for given schemes and operating parameters [1-4]. For these programs, in order to evaluate any one or several parameters of the regime, each time it is required to carry out calculations on a computer according to the complete scheme with the corresponding preparation of the initial data. In addition, the initial information required for calculations due to the imperfection of the information transmission and processing system is often probabilistic or partially uncertain. In such cases, the calculation results differ from the actual parameters of the regime, which, naturally, reduces the value of the calculation model, which has a high accuracy.

In such conditions, the parameters of the regime obtained as a result of deterministic calculations are point estimates of a separate regime situation and it is not possible to establish causal relationships between controlled and controlled factors and, therefore, analyze the regime in the dynamics of its change and control it in the desired direction. In connection with these circumstances, under conditions of a probabilistic nature and uncertainty of the initial information, the problem should be solved based on the use of appropriate algorithms and programs [5-7].

In the short-term planning of EPS modes, the initial information, which is probabilistic or partially uncertain, is often the node loads determined by the appropriate prediction methods.

The main characteristic of probabilistic information is the distribution laws of the initial parameters in a known range of their variation. In the presence of statistical data on the values of such parameters, the laws of their distribution can be obtained by processing these data. 


\section{Main part}

Optimization under the conditions of the probabilistic nature of the initial parameters can be carried out, in particular, based on the search for the extreme of the mathematical expectation of the objective function, as in [3]. In this case, the specified range of variation of the initial parameter $x$ is divided into $m$ sections, in which it has values $x_{1}, x_{2}, \ldots, x_{m}$ with the probabilities of occurrence, in accordance with a given distribution law , $p_{1}, p_{2}, \ldots, p_{m}$, respectively. Then the deterministic optimization problem is solved $m$ times taking into account all the constraints for the values of the initial parameter $x_{1}, x_{2}, \ldots, x_{m}$, as a result, conditionally optimal plans $z_{1}, z_{2}, \ldots, z_{m}$ are found. Based on the known values of the initial parameter and the obtained conditionally optimal plans, the corresponding values of the objective function are calculated, which is, for example, the function of total costs in the EPS $3_{i j}=f\left(z_{i}\right.$, $\left.x_{j}\right)(i=1,2, \ldots, m, j=1,2, \ldots, m)$. Based on these values of the objective function, a payment matrix is formed. Then, for each conditionally optimal design $z_{t}$, the mathematical expectations of the objective function are calculated.

$$
\mathrm{M}_{t}=\sum_{j=1}^{m} p_{j} 3_{t j}
$$

The design $z_{t}$ which provides the minimum mathematical expectation of the objective function is optimal.

If the initial parameters are two parameters $x_{j}$ and $y_{k}$ with the probabilities of occurrence $p_{j}$ and $p_{k}$ then the optimal plan $z_{t}$ is found from the condition of the minimum mathematical expectation of the objective function determined by the formula:

$$
\mathrm{M}_{t}=\sum_{j} \sum_{k} p_{j} p_{k} 3_{t j k}
$$

With a large number of initial probabilistic parameters, the problem becomes rather complicated, but, in the conditions of the capabilities of modern computing facilities, it can be solved.

Studies have established that in the presence of functional constraints in the form of inequalities for some conditionally optimal designs obtained by the above algorithm and the conditions for their implementation, these constraints can be violated (table 3 ). In such cases, conditionally optimal designs are invalid. Therefore, here we propose an algorithm for taking into account such restrictions, according to which, together with the payment matrix, similar matrices are formed, consisting of the values of the restriction functions. Then, before proceeding with the calculation of the mathematical expectations of the objective function, those conditionally optimal plans are excluded from further consideration, for which at least one implementation condition is violated [8-12]. Then the mathematical expectations are calculated for the remaining conditionally optimal plans, according to which the optimal plan is determined.

We investigate the efficiency of the described algorithm using the example of the optimal distribution of the EPS load, the diagram of which is shown in Fig. 1, between three TPPs. Fuel cost characteristics of TPPs:

$$
\begin{aligned}
& B_{1}\left(P_{1}\right)=3+0,019 P_{1} \$ / \text { hour; } \\
& B_{2}\left(P_{2}\right)=5+0,014 P_{2} \$ / \text { hour; } \\
& B_{6}\left(P_{6}\right)=3+0,016 P_{6} \$ / \text { hour. }
\end{aligned}
$$

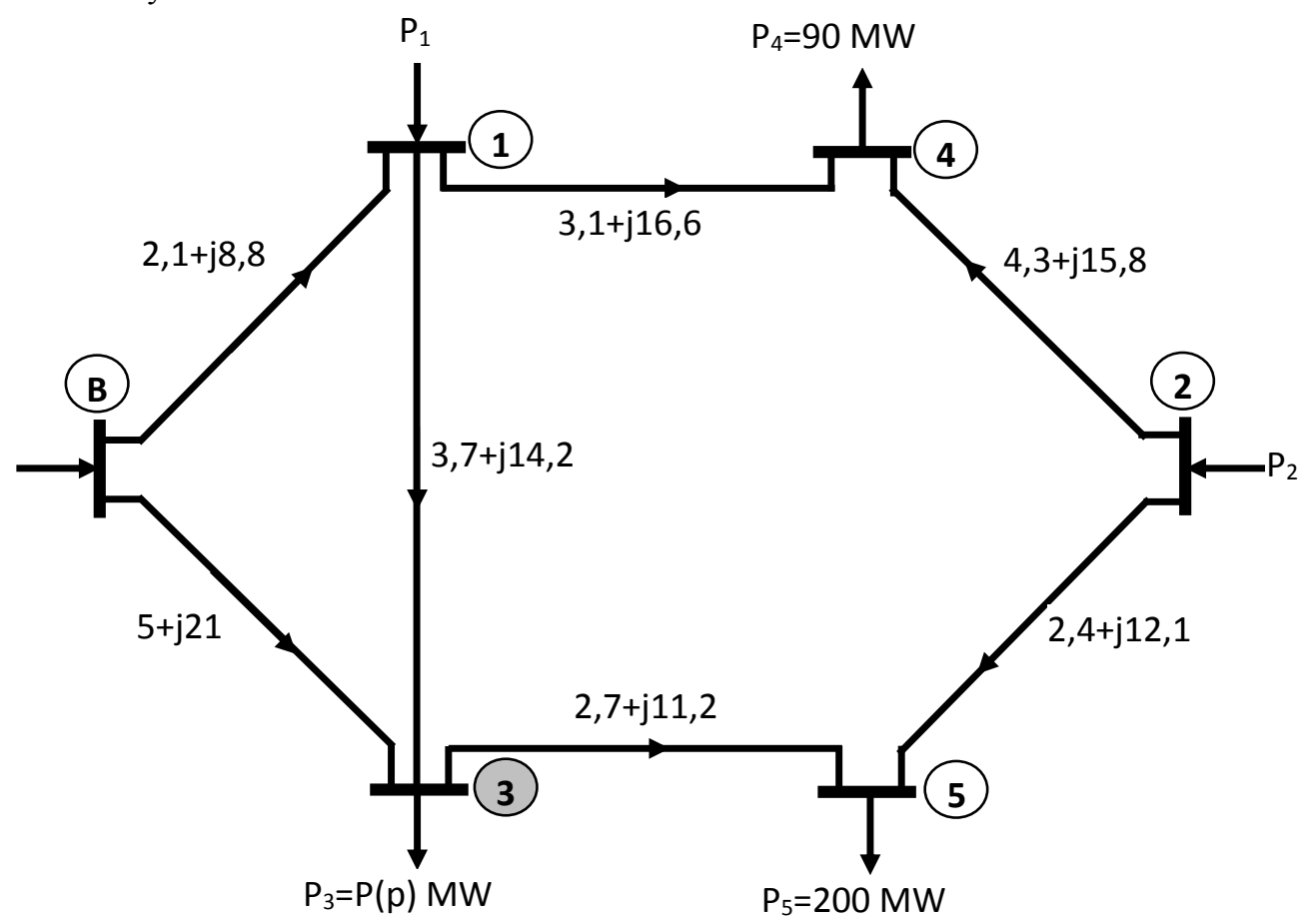

Fig. 1. Electric network diagram of the electric power plant. 
The load at node 3 is probabilistic. Possible values of the load of this node and the probability of their occurrence (distribution law) are given in table 1.

Active power flows are monitored in two lines :

$$
\mathrm{P}_{1-3} \leq 157 \mathrm{MW}, \quad \mathrm{P}_{\mathrm{b}-3} \leq 136 \mathrm{MW} .
$$

Active power flows through controlled lines are determined by distribution coefficients [13-16].

We carry out optimization calculations according to the above algorithm. As a result, we obtain a payment matrix (table 2), consisting of the values of the objective function, which is a function of total fuel costs for various conditionally optimal plans and load values of node 3 .

Table 1. Probable loads of node 3 and probability of their occurrence

\begin{tabular}{|l|c|c|c|c|c|}
\hline Loads node, MW & 165 & 180 & 212 & 223 & 234 \\
\hline $\begin{array}{l}\text { Probability } \\
\text { appearance }\end{array}$ & 0.1 & 0.15 & 0.5 & 0.15 & 0.1 \\
\hline
\end{tabular}

Table 2. Payment Matrix

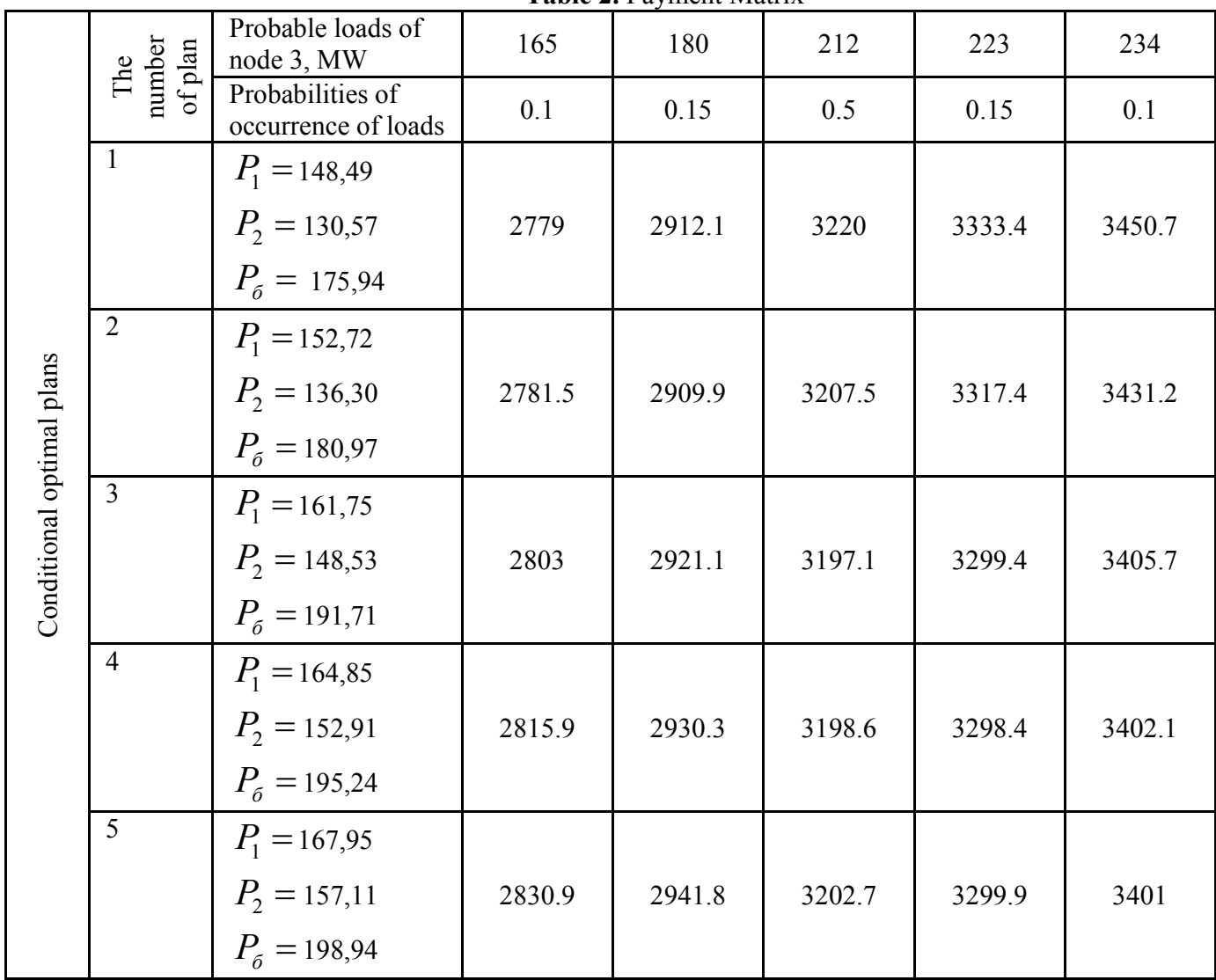

We find the mathematical expectations of the objective function - the function of total fuel costs in the power system for each of the conditionally optimal plans:

$$
\begin{aligned}
& M B(1)=3169,8 \$ / \text { hour, } \\
& M B(2)=3159,1 \$ / \text { hour, } \\
& M B(3)=3152,5 \$ / \text { hour, } \\
& M B(4)=3155,4 \$ / \text { hour, } \\
& M B(5)=3160,8 \$ / \text { hour. }
\end{aligned}
$$

We find the optimal plan by the condition of the minimum mathematical expectation:

$$
\min M \pi(i)=M \pi(3)=3152,5 \$ / \text { час }
$$

Thus, disregarding the technological constraint, the optimal plan is 3 , in which

$$
\begin{aligned}
& P_{1}^{\text {onm }}=161,75 \mathrm{MW} ; \\
& P_{2}^{\text {onm }}=148,53 \mathrm{MW} ; \\
& P_{\sigma}^{\text {onm }}=191,71 \mathrm{MW} .
\end{aligned}
$$

To take into account the functional restrictions according to the proposed algorithm, we form similar matrices consisting of the values of the power flows along the controlled lines. For convenience, Table 3 shows the maximum values of power flows for each conditionally optimal plan. 
Table 3. Maximum power flow values for each conditional optimal plan

\begin{tabular}{|c|c|c|c|c|}
\hline $\begin{array}{c}\text { The number is conditionally optimal. Plan } \\
\text { according to table. } 1\end{array}$ & Total load of EPS, MW & $P_{1-3, M W}$ & $P_{B-3, M W}, \$ /$ hour \\
\hline 1 & 455 & 157.28 & 147.28 & 3169.8 \\
\hline 2 & 470 & 157.05 & 144.23 & 3159.1 \\
\hline 3 & 502 & 156.57 & 137.72 & 3152.5 \\
\hline 4 & 513 & 156.38 & 135.42 & 3155.4 \\
\hline 5 & 524 & 156.21 & 133.18 & 3160.8 \\
\hline
\end{tabular}

Table 3. The results of calculating the maximum values of power flows along the controlled lines for various conditionally optimal plans [17-21].

Based on the analysis of Table 2, we reveal that only with the 4th and 5th conditionally optimal plans, the restrictions are not violated. Therefore, we are looking for the optimal plan, taking into account the constraints, among these two admissible conditionally optimal plans for the minimum mathematical expectation of the objective function: \$ 3155.4 / hour; \$ 3160.8 / hour [2226].

The mathematical expectation for the 4th conditionally optimal plan is the smallest, therefore the optimal plan for the problem under consideration is plan 4 :

$$
\begin{aligned}
& P_{1}^{\text {onm }}=164,85 \mathrm{MW} ; \\
& P_{2}^{\text {onm }}=152,91 \mathrm{MW} ; \\
& P_{\sigma}^{\text {onm }}=195,24 \mathrm{MW}, \\
& \min M B(i)=M \pi(4)=3155,4 \text { \$/hour. }
\end{aligned}
$$

\section{Conclusions}

1. An algorithm for optimization of power systems modes is proposed, taking into account simple and functional constraints in the form of inequalities under conditions of the probabilistic nature of the initial nodal information, based on the use of payment matrices of the objective function and constraint functions. As a result, it is possible to optimize short-term modes of power systems with high accuracy, taking into account the constraints in the form of inequalities in the conditions of the probabilistic nature of the loads of electrical consumers.

2. On the basis of research, it has been revealed that in the presence of functional constraints in the form of inequalities for some conditionally optimal plans, these constraints may be violated. Accordingly, such conditionally optimal designs are invalid. Here is an algorithm for taking into account such restrictions, according to which matrices similar to the payment matrix are also formed according to the values of the function taking into account such restrictions. Then, conditionally optimal plans are allocated, in which not one of the functional constraints is violated.

\section{References}

1. Koptsev L A, Koptsev A L 2011 Rationing and forecasting of electricity consumption in an industrial enterprise $J$ Industrial power engineering. 1 pp 18-23
2. Hoshimov FA, Rahmonov I U 2014 Rationing of electricity production in the rolling of ferrous metallurgy $J$ European Science review 11-12 pp 56-59

3. Saidkhodjaev A G, Najimova A M and Bijanov A K 2019 Method for determining the maximum load of consumers in city power supply systems E3S Web Conf 139 doi:10.1051/e3sconf/201913901078.

4. Taslimov A D, Rakhmonov I U 2019 Optimization of complex parameters of urban distribution electric networks Journal of Physics: Conference Series 1399 doi:10.1088/1742-6596/1399/5/055046

5. Rakhmonov I U, Niyozov N N 2019 Optimization setting of steel-smelting industry in the issue of alloy steels $\quad E 3 S \quad$ Web Conf 139 doi:10.1051/e3sconf/201913901077

6. Rakhmonov I U, Nematov L A, Niyozov N N, Reymov K M and Yuldoshev T M 2020 Power consumption management from the positions of the general system theory Journal of Physics: Conference Series 1515 doi:10.1088/1742-6596/1515/2/022054

7. Taslimov A D, Berdishev A S, Melikuzuev M V and Rakhimov F M 2019 Method of selecting parameters of cable lines distributive networks $10 \mathrm{kv}$ in uncertainty conditions $\quad E 3 S \quad W e b \quad$ Conf 139 doi:10.1051/e3sconf/201913901082

8. Taslimov A D, Berdishev A S, Melikuziyev M V and Rakhimov F M 2019 Method of choosing the unification of cable sections of electric network cables under conditions of load development uncertainty E3S Web Conf 139 doi:10.1051/e3sconf/201913901081

9. Rakhmonov, I.U., Nematov, L.A., Niyozov, N.N, Reymov, K.M., Yuldoshev, T.M. (2020) Power consumption management from the positions of the general system theory Journal of Physics: Conference Series 1515 doi:10.1088/1742-6596/1515/2/022054

10. Rakhmonov, I.U., Berdishev, A.A., Khusanov, B.M., Khaliknazarov, U., Utegenov, U. (2020) General characteristics of networks and features of electricity consumers in rural areas Journal of IOP: Conference Series. MIP: Engineering-2020. 883 (2020) 012104 doi:10.1088/1757-899X/883/1/012104

11. Karimov R.Ch., Shamsiyev K., and others. IOP Conf. Series: Materials Science and Engineering, 883(1), 012142, (2020). doi:10.1088/1757-899X/883/1/012142 12. Karimov R.Ch., Shamsiyeva N. and others. IOP Conf. Series: Materials Science and Engineering, 883(1), 012120, (2020). doi:10.1088/1757-899X/883/1/012120

13.E.G.Usmanov, A.N.Rasulov, M.K.Bobojanov, R.Ch.Karimov. E3S Web of Conferences 139, 01079 (2019), doi.org/10.1051/e3sconf/201913901079

14. Bobojanov M.K., Rasulov A.N., Karimov R.Ch., Sattarov H.A. Bulletin Descendants of Mohammed Al- 
Khwarizmi (ISSN: 2181-9211), Tashkent, 3(5), - PP.106109, (2018).

15. Burievich, T.J. The questions of the dynamics of drilling bit on the surface of well bottom// Arch. Min. Sci. -Poland. - Vol. 61 (2016). - №2. - P. 279-287. DOI 10.1515/amsc-2016-0020.

16. Toshniyozov, L.G., Toshov, J.B. Theoretical and experimental research into process of packing in drilling// Mining Informational and Analytical Bulletin Volume 2019, Issue 11, 2019, Pages 139-151. DOI: 10.25018/0236-1493-2019-11-0-139-151.

17. Avezova N.R., Toshov J.B., Dalmuradova N.N., Farmonova A.A., Mardonova M.Sh.Renewable Energy: Scenario and Model of Development // ISSN 0003-701X, Applied Solar Energy, 2019, Vol. 55, No. 6 , pp. 438-445. DOI: 10.3103/S0003701X19060021

18. Mannanov U., Toshov J., Toshniyozov L. Perspective Solutions for the Design of Drilling Tools / E3S Web of Conferences 105, 03027 (2019) IVth International Innovative Mining Symposium, https://doi.org/10.1051/e3sconf/201910503027

19. Toshov J., Saitov E. Portable autonomous solar power plant for individual use / E3S Web Conf., Volume 139, 01087, 2019, Rudenko International Conference "Methodological problems in reliability study of large energy systems" (RSES 2019), https://doi.org/10.1051/e3sconf/201913901087

20. Azamatovich, A.N., Amrillo, M.B, Burievich, T.J., Umarxanoxich, J.R., Shavkatovich, Z.A. A complex of methods for analyzing the working fluid of a hydrostatic power plant for hydraulic mining machines / International Journal of Advanced Science and Technology. Volume 29, Issue 5 Special Issue, 28 March 2020, Pages 852-855

21. Hoshimov, F.A., Bakhadirov, I.I., Erejepov, M., Djumamuratov, B. (2019) Development of method for normalizing electricity consumption E3S Web Conf 139 doi:10.1051/e3sconf/201913901074

22. Allayev, K.R., Fedorenko, G.M.,Postnikov, V.I.,Ostapchuk, L.B. Asynchronous generators as power system's natural dampers. 43rd International Conference on Large High Voltage Electric Systems 2010, CIGRE 20102010, 9p43rd International Conference on Large High Voltage Electric Systems 2010, CIGRE 2010; Paris; France; 22 August 2010.

23.Fazylov, Kh.F.,Allaev, K.R. Asynchronous turbogenerators with stator excitation and the prospects for their utilization. Power engineering New York Volume 23, Issue 2, 1985, Pages 7-13.

24.Fazylov, Kh.F.,Allaev, K.R. Calculation and experimental analysis of conditions of electrical power systems containing induction generators Power Engineering New York Volume 27, Issue 6, 1989, Pages 27-34.

25.Allaev K., Makhmudov T. Research of small oscillations of electrical power systems using the technology of embedding systems. Electrical Engineering, 2020; Issue 1: 309-319.DOI 10.1007/s00202-019-00876-9

26.Allaev K., Makhmudov T. Prospects of diversification and ensuring energy safety of Uzbekistan. E3S Web Conf., Volume 139, 2019, Rudenko International
Conference "Methodological problems in reliability study of large energy systems" (RSES 2019).https://doi.org/10.1051/e3sconf/201913901002 